\title{
Ventriculoarterial coupling in palliated hypoplastic left heart syndrome: Noninvasive assessment of the effects of surgical arch reconstruction and shunt type
}

\author{
Giovanni Biglino, PhD, Alessandro Giardini, MD, Hopewell N. Ntsinjana, MD, Silvia Schievano, PhD, \\ Tain-Yen Hsia, MD, and Andrew M. Taylor, MD, for the Modeling of Congenital Hearts Alliance \\ Collaborative Group
}

Objective: To assess the coupling efficiency in hypoplastic left heart syndrome, considering the effect of surgical arch reconstruction and the shunt type received during the Norwood procedure.

\begin{abstract}
Methods: Ventriculoarterial coupling was assessed before Fontan completion in 32 patients with hypoplastic left heart syndrome (19 modified Blalock-Taussig and 13 Sano shunts at stage 1). Cardiovascular magnetic resonance data were analyzed, deriving functional parameters and 3-dimensional volumes. Dimensional indexes were computed from 3-dimensional data sets as the area ratio of the isthmus to the descending aorta $\left(R_{\text {isthmus }}\right)$ and the isthmus to surgically enlarged transverse arch $\left(R_{\text {arch }}\right)$. Wave intensity was calculated from cardiac magnetic resonance, using the peaks of the forward compression and expansion waves in early and late systole as surrogate indicators of ventriculoarterial coupling.
\end{abstract}

\begin{abstract}
Results: Aortic distensibility $\left(3.6 \pm 2.7 \times 10^{-3} 1 / \mathrm{mm} \mathrm{Hg}\right)$ was not associated with the time elapsed from stage 1 palliation $(P=.94)$, suggesting an early loss of elasticity that did not progress thereafter. $R_{\text {isthmus }}$ was $1.0 \pm 0.4$, and $R_{\text {arch }}$ was $0.3 \pm 0.1$, indicating the dilated reconstructed arch was the main anatomic feature. The forward compression wave correlated significantly with $R_{\text {arch }}\left(\mathrm{R}^{2}=0.23, P=.006\right)$ but not with $R_{\text {isthmus }}\left(\mathrm{R}^{2}<0.01, P=.63\right)$. Patients with a reduced ejection fraction exhibited a larger ventricular mass $\left(\mathrm{R}^{2}=0.28, P=.003\right)$. The Sano shunt patients had a lower ejection fraction $(51 \% \pm 6 \%$ vs $57 \% \pm 6 \%, P=.02)$; however, neither the forward compression nor expansion wave varied significantly between shunt type or the other functional parameters.
\end{abstract}

Conclusions: Ventriculoarterial coupling in operated hypoplastic left heart syndrome was affected by aortic arch size mismatch but not by the type of shunt placed at the Norwood operation. (J Thorac Cardiovasc Surg 2014;148:1526-33)

From the Centre for Cardiovascular Imaging, UCL Institute of Cardiovascular Science, University College London, and Cardiorespiratory Division, Great Ormond Street Hospital for Children, National Health Service Foundation Trust, London, United Kingdom.

This study was supported by the following funding bodies: Fondation Leducq, UK National Institute of Health Research, British Heart Foundation, Royal Academy of Engineering/EPSRC, and Heart Research UK.

This report was independent research by the National Institute for Health Research Biomedical Research Centre Funding Scheme. The views expressed in this publication are those of the authors and not necessarily those of the National Health Service, National Institute for Health Research, or Department of Health.

Disclosures: Authors have nothing to disclose with regard to commercial support. Drs Biglino and Giardini contributed equally to this publication.

Modeling of Congenital Hearts Alliance (MOCHA) Group: Andrew Taylor, MD, Alessandro Giardini, MD, Sachin Khambadkone, MD, Silvia Schievano, PhD, Marc de Leval, MD, and T.-Y. Hsia, MD (UCL Institute of Cardiovascular Science, University College London, London, UK); Edward Bove, MD, and Adam Dorfman, MD (University of Michigan, Ann Arbor, Mich); G. Hamilton Baker, MD, and Anthony Hlavacek, MD (Medical University of South Carolina, Charleston, SC); Francesco Migliavacca, PhD, Giancarlo Pennati, PhD, and Gabriele Dubini, PhD (Politecnico di Milano, Milan, Italy); Alison Marsden, $\mathrm{PhD}$ (University of California, San Diego, Calif, USA); Jeffrey Feinstein, MD (Stanford University, Stanford, Calif); Irene Vignon-Clementel (Inventeurs du Monde Numérique, Paris, France); and Richard Figliola, $\mathrm{PhD}$, and John McGregor, $\mathrm{PhD}$ (Clemson University, Clemson, SC).

Received for publication Nov 12, 2013; revisions received Jan 21, 2014; accepted for publication Feb 3, 2014; available ahead of print March 12, 2014

Address for reprints: Giovanni Biglino, $\mathrm{PhD}$, Centre for Cardiovascular Imaging, UCL Institute of Cardiovascular Sciences, University College London, and Cardiorespiratory Division, Great Ormond Street Hospital for Children, Great Ormond St, London WC1N 3JH, United Kingdom (E-mail: g.biglino@ucl.ac.uk). $0022-5223 / \$ 36.00$

Copyright $($ c 2014 by The American Association for Thoracic Surgery

http://dx.doi.org/10.1016/j.jtcvs.2014.02.012
Right ventricular (RV) dysfunction is an important contributor to mortality and morbidity in children with hypoplastic left heart syndrome (HLHS), and abnormal afterload contributes to this. It has been observed that intermediate and overall survival has been poorer in patients with initially diminished RV function. ${ }^{1}$ It has also been suggested that afterload reduction in this population could avoid preoperative artificial respiration, which can be a risk factor for in-hospital mortality. ${ }^{2}$

Increased afterload can result from different causes in operated HLHS. Although the contribution of aortic repeat coarctation has been extensively studied, ${ }^{3}$ another recently identified contributor to increased afterload is the impedance generated by the surgically repaired hypoplastic ascending aorta. At first stage palliation of HLHS (ie, during the Norwood procedure), ${ }^{4}$ the ascending/ transverse aorta will be enlarged with a patch of varying extent, typically sourced from pulmonary homograft material. ${ }^{5}$ The presence of the additional tissue and its degeneration with time are likely contributors to the decreased ascending aortic distensibility that has been well documented in patients after stage 1 surgery. ${ }^{6-8}$

Additional considerations on distensibility have recently been gathered noninvasively, using imaging-based wave 


$$
\begin{aligned}
& \text { Abbreviations and Acronyms } \\
& \begin{aligned}
3 \mathrm{D} & =3 \text {-dimensional } \\
\mathrm{A}_{\mathrm{d}} & =\text { descending aorta cross-sectional area } \\
\mathrm{A}_{\mathrm{n}} & =\text { cross-sectional area at the isthmus } \\
\mathrm{A}_{\mathrm{t}} & =\text { transverse arch cross-sectional area } \\
\mathrm{CMR} & =\text { cardiac magnetic resonance } \\
\mathrm{EF} & =\text { ejection fraction } \\
\mathrm{FCW} & =\text { forward compression wave } \\
\mathrm{FEW} & =\text { forward expansion wave } \\
\mathrm{HLHS} & =\text { hypoplastic left heart syndrome } \\
\mathrm{mBT} & =\text { modified Blalock-Taussig } \\
\mathrm{RV} & =\text { right ventricular } \\
\mathrm{VA} & =\text { ventriculoarterial }
\end{aligned}
\end{aligned}
$$

intensity analysis using cardiovascular magnetic resonance (CMR) imaging data. This has shown the interaction between the single ventricle and the systemic vasculature in 2 small cohorts of patients with a single ventricle, with and without surgical arch reconstruction. ${ }^{9}$ That study demonstrated that reduced aortic distensibility in Norwood patients, related to the presence of the aortic patch, chronically increases the burden of afterload on the systemic right ventricle by worsening ventriculoarterial

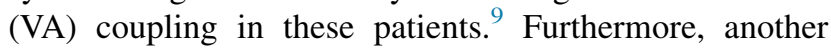
imaging study of phase-contrast CMR measurements, comparing children with HLHS and other single ventricle physiologies, observed lower power output and cardiac index in the HLHS group and an increased systemic vascular resistance index despite similar blood pressure levels. ${ }^{10}$

Another variable that could affect VA coupling in these patients is the type of shunt received at the Norwood operation. Hemodynamic differences between stage 1 palliation performed using a modified Blalock-Taussig (mBT) shunt ${ }^{11}$ or a Sano shunt ${ }^{12}$ have been extensively discussed in the clinical data. ${ }^{13-15}$ However, the potential for a different effect on VA coupling has not been fully investigated. This is relevant, not only for the different loading conditions, but also for the effect of the ventriculotomy in Sano patients on global and segmental RV systolic function. ${ }^{16}$

Therefore, the present study investigated the effects of surgical arch reconstruction and shunt type at the Norwood procedure on VA coupling in a group of patients with HLHS before Fontan completion.

\section{METHODS \\ Patients}

This was a single-center retrospective study of 32 children (age, $3.2 \pm 0.9$ years; body surface area, $0.6 \pm 0.1 \mathrm{~m}^{2} ; 23$ males) with HLHS palliated according to the Norwood operation. All patients underwent a comprehensive CMR examination as preparation for completion of a total cavopulmonary connection. At stage 1 surgery,
19 children $(59 \%)$ received an $\mathrm{mBT}$ shunt, and $13(41 \%)$ received a Sano shunt. The decision about the shunt type was determined mainly by era and surgeon preference. All patients had undergone aortic arch reconstruction and coarctectomy. A homograft patch was used in all cases. Some of the patients had presented with varying degrees of aortic coarctation, and a size mismatch between the surgically enlarged transverse aorta and the native descending thoracic aorta could be qualitatively appreciated from the imaging data. All the parents had provided informed consent, and the institutional research ethics committee approved the study. The demographic characteristics are listed in Table 1.

\section{CMR Imaging}

CMR was acquired using a $1.5 \mathrm{~T}$ scanner (Avanto; Siemens Medical Solutions, Erlangen, Germany). Through-plane flow data $(\sim 30 \mathrm{~ms}$ temporal resolution, interpolated to 30 frames/heart beat) were acquired using retrospective cardiac gating. Retrospectively gated, balanced steady state free precession cine images of the heart were acquired in the 4-chamber, long-axis, and short-axis views covering the entirety of the ventricle (9-12 slices). The single ventricle indexed end-diastolic and end-systolic volumes were measured, and the stroke volume, ejection fraction, and cardiac output were derived from these. The ventricular mass was obtained by manually tracing the epicardial and endocardial borders of the CMR short-axis stack at the end of systole, and the obtained value was then indexed by body surface area $\left(\mathrm{g} / \mathrm{m}^{2}\right)$. Phase-contrast CMR acquisitions were used for flow quantification. Postprocessing was performed with in-house written plug-ins (OsiriX; Pixmeo, Geneva, Switzerland ${ }^{17}$ ). It was ensured that the imaging plane was always above the aortic-pulmonary anastomosis to ensure that the reconstructed (patched) portion of the aorta was captured. The ascending aortic data were always acquired just above the Damus-Kaye-Stansel anastomosis, according to our institutional pre-Fontan completion protocol.

Three-dimensional (3D) volumes were obtained in all cases from the 3D whole-heart sequence using commercial software (Mimics; Materialise, Leuven, Belgium) after operations of thresh-holding, segmentation, volume rendering, and smoothing. ${ }^{18}$ The volumes were used, not only to better appreciate the anatomy of each patient, but also to select the following planes:

1. Transverse arch (between the left subclavian and the left carotid)

2. Isthmus (maximum narrowing in the area of previous repair)

3. Descending aorta (at the level of the diaphragm)

These identified cross-sections were used to calculate the respective areas $\left(A_{t}\right.$, transverse arch cross-sectional area; $A_{n}$, cross-sectional area at the isthmus, and $A_{d}$, descending aorta cross-sectional area), and, in turn, these were used to calculate 2 nondimensional ratios (isthmus ratio $=R_{\text {isthmus }}=\mathrm{A}_{\mathrm{n}} / \mathrm{A}_{\mathrm{d}}$; and arch ratio $=R_{\text {arch }}=\mathrm{A}_{\mathrm{n}} / \mathrm{A}_{\mathrm{t}}$ ) to assess the presence of aortic coarctation per se (ie, $R_{\text {isthmus }}$ equivalent to the coarctation index), as defined by Lemler and colleagues, ${ }^{19}$ but also the presence of size mismatch, which was more likely indicated by $R_{\text {arch }}$. A sample of 3D volumes and aortic planes for the isthmus and area ratio calculation is shown in Figure 1.

\section{Data Analysis}

In addition to the CMR functional data (EF, indexed end-diastolic and end-systolic volumes, indexed single ventricle mass), other parameters were included in the analysis. Using a method described in a previous study, ${ }^{20}$ the wave speed (c) was calculated from the phase contrast ascending aortic flow data by relating the aortic blood flow velocity and changes in the aortic area, in accordance with a modified water hammer equation:

$$
\mathrm{dU}_{ \pm}= \pm \mathrm{cdln} \mathrm{A}_{ \pm}
$$


TABLE 1. Patient characteristics

\begin{tabular}{|c|c|c|c|c|c|c|}
\hline Pt. no. & Age at Glenn (mo) & EF $(\%)$ & Shunt type & Anatomic substrate/comments & RV status & $\mathrm{SaO}_{2}(\%)$ \\
\hline 1 & 8.2 & 55 & Sano & HLHS & Hypertrophied & 77 \\
\hline 2 & 3.1 & 43 & Sano & HLHS, aortic and mitral atresia & Dilated and hypertrophied & 87 \\
\hline 3 & 4.4 & 57 & $\mathrm{mBT}$ & HLHS & $\begin{array}{l}\text { Dilated and moderately } \\
\text { hypertrophied }\end{array}$ & 89 \\
\hline 4 & 5.4 & 52 & $\mathrm{mBT}$ & $\begin{array}{l}\text { Tricuspid atresia, ASD, VSD, } \\
\text { hypoplastic aortic arch, coarctation }\end{array}$ & Mildly impaired & - \\
\hline 5 & 6.6 & 60 & Sano & $\begin{array}{l}\text { HLHS, } 2 \times \text { catheter balloon dilations } \\
\text { of transverse aortic arch }\end{array}$ & Dilated and hypertrophied & - \\
\hline 6 & 5.1 & 54 & $\mathrm{mBT}$ & HLHS & Dilated and hypertrophied & 85 \\
\hline 7 & 4.6 & 51 & $\mathrm{mBT}$ & $\begin{array}{l}\text { HLHS, mitral and aortic stenosis, } \\
\text { aortic coarctation, Jacobsen } \\
\text { syndrome }\end{array}$ & Hypertrophied & 85 \\
\hline 8 & 2.3 & 45 & Sano & HLHS & Dilated and hypertrophied & 89 \\
\hline 9 & 7.0 & 51 & $\mathrm{mBT}$ & Left aortic arch hypoplasia & Dilated & 92 \\
\hline 10 & 6.9 & 48 & Sano & $\begin{array}{l}\text { HLHS, moderate aortic arch } \\
\text { obstruction }\end{array}$ & - & - \\
\hline 11 & 3.1 & 57 & $\mathrm{mBT}$ & HLHS & Good RV function & - \\
\hline 12 & 4.6 & 58 & $\mathrm{mBT}$ & HLHS & Moderately dilated and hypertrophied & 87 \\
\hline 13 & 5.1 & 52 & Sano & HLHS & Dilated and hypertrophied & 92 \\
\hline 14 & 1.3 & 64 & $\mathrm{mBT}$ & $\begin{array}{l}\text { HLHS, mitral and aortic stenosis with } \\
\text { severe LV hypoplasia }\end{array}$ & Hypertrophied and dilated & 84 \\
\hline 15 & 14.7 & 42 & Sano & HLHS & Severely dilated and hypertrophied & 86 \\
\hline 16 & 3.6 & 56 & $\mathrm{mBT}$ & HLHS & $\begin{array}{l}\text { Dilated and hypertrophied, RV } \\
\text { diastolic dysfunction seen on } \\
\text { tricuspid valve inflow pattern }\end{array}$ & 81 \\
\hline 17 & 3.6 & 63 & $\mathrm{mBT}$ & HLHS & Dilated and hypertrophied & 90 \\
\hline 18 & 5.8 & 44 & $\mathrm{mBT}$ & HLHS & $\begin{array}{l}\text { Moderately-severely hypertrophied } \\
\text { and dilated }\end{array}$ & 83 \\
\hline 19 & 6.5 & 51 & Sano & HLHS & Moderately hypertrophied & 86 \\
\hline 20 & 21.8 & 54 & $\mathrm{mBT}$ & HLHS & $\begin{array}{l}\text { Moderately dilated and severely } \\
\text { hypertrophied }\end{array}$ & 95 \\
\hline 21 & 3.4 & 53 & Sano & $\begin{array}{l}\text { HLHS, mitral and aortic atresia, } \\
\text { dilated RA }\end{array}$ & Dilated and hypertrophied & - \\
\hline 22 & 7.4 & 56 & Sano & $\begin{array}{l}\text { HLHS, aortic atresia, functional } \\
\text { mitral atresia }\end{array}$ & Moderately hypertrophied & - \\
\hline 23 & & 61 & Sano & HLHS & Mildly hypertrophied & 85 \\
\hline 24 & 3.9 & 55 & $\mathrm{mBT}$ & HLHS & RV diastolic dysfunction & - \\
\hline 25 & 4.7 & 48 & $\mathrm{mBT}$ & $\begin{array}{l}\text { HLHS, tricuspid valve replacement } \\
\text { with mechanical valve }\end{array}$ & $\begin{array}{l}\text { Hypertrophied, "jerky" relaxation } \\
\text { suggesting diastolic dysfunction }\end{array}$ & 87 \\
\hline 26 & 4.2 & 66 & $\mathrm{mBT}$ & HLHS & $\begin{array}{l}\text { Dilated and moderately } \\
\text { hypertrophied }\end{array}$ & 93 \\
\hline 27 & 4.4 & 64 & $\mathrm{mBT}$ & HLHS & Dilated and hypertrophied & 91 \\
\hline 28 & 4.4 & 61 & $\mathrm{mBT}$ & HLHS & Dilated and hypertrophied & 91 \\
\hline 29 & 2.1 & 49 & Sano & HLHS, significant coarctation & $\begin{array}{l}\text { Moderately dilated and severely } \\
\text { hypertrophied }\end{array}$ & 86 \\
\hline 30 & 3.3 & 52 & Sano & $\begin{array}{l}\text { HLHS, mitral and aortic atresia, } \\
\text { balloon dilation of aortic arch } \\
\text { obstruction }\end{array}$ & Dilated and hypertrophied & 88 \\
\hline 31 & 4.3 & 67 & $\mathrm{mBT}$ & $\begin{array}{l}\text { HLHS, abrupt tapering transverse } \\
\text { aortic arch }\end{array}$ & Dilated and hypertrophied & 94 \\
\hline 32 & 3.7 & 54 & $\mathrm{mBT}$ & HLHS, aortic coarctation & Dilated and hypertrophied & 89 \\
\hline
\end{tabular}

Pt. No., Patient number; $E F$, ejection fraction; $R V$, right ventricular; $\mathrm{SaO}_{2}$, oxygen saturation; $m B T$, modified Blalock-Taussig; $H L H S$, hypoplastic left heart syndrome; $A S D$, atrial septal defect; $V S D$, ventricular septal defect; $L V$, left ventricular; $R A$, right atrium. 

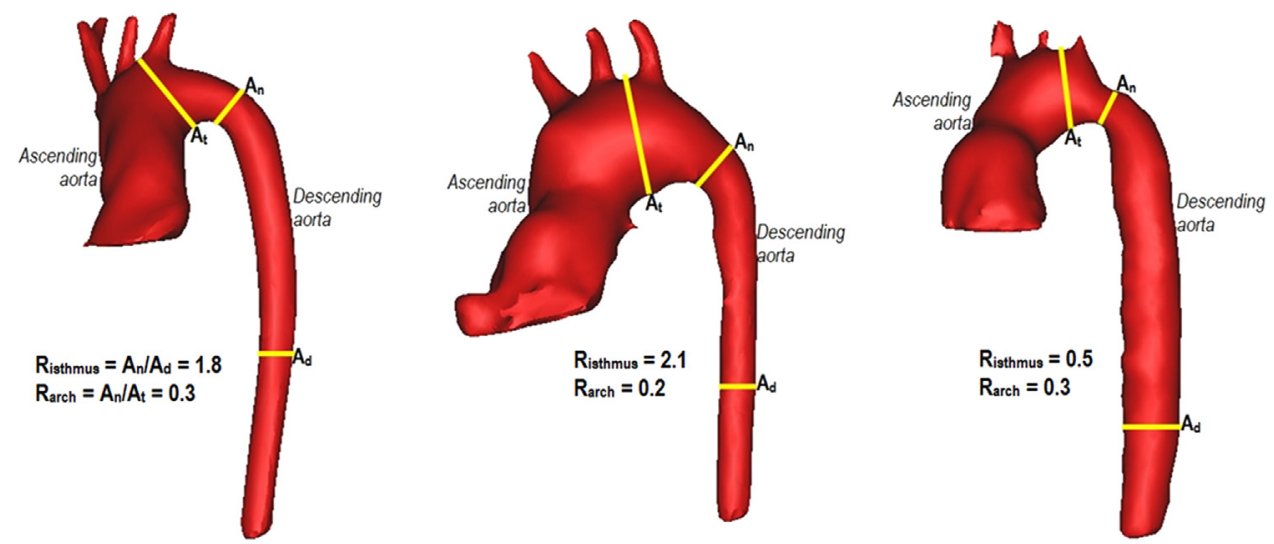

FIGURE 1. Examples of 3-dimensional (3D) volumes obtained from the 3D whole heart sequences, highlighting the planes selected for calculation of the cross-sectional areas of the transverse $\operatorname{arch}\left(A_{t}\right)$, isthmus/narrowing $\left(A_{n}\right)$, and descending aorta $\left(A_{d}\right)$. Two coractation indexes were computed for each patient (area ratio of the isthmus to the descending aorta $\left[R_{\text {isthmus }}\right]$ and of the isthmus to the surgically enlarged transverse $\operatorname{arch}\left[R_{\text {arch }}\right]=\mathrm{A}_{\mathrm{n}} / \mathrm{A}_{\mathrm{t}}$ ).

Knowledge of the wave speed c allows for direct calculation of aortic distensibility (D), according to the Bramwell-Hill equation:

$$
\mathrm{D}=1 / \rho \mathrm{c}^{2}
$$

where $\rho$ is the density of blood. An example of wave speed calculation from the CMR data is shown in Figure 2, A. Semiautomatic segmentation of the phase contrast ascending aortic flow sequence for each patient also yielded information on the wave intensity. CMR-derived wave intensity analysis ${ }^{19}$ was defined as the instantaneous product of changes in blood flow velocity and fractional changes in area:

$$
\mathrm{dl}=\mathrm{dUdln} \mathrm{A}
$$

This quantity can be insightful regarding the changes in VA coupling, because wave intensity is a measure of energy flux per unit area and, as a hemodynamic index, is an indicator of the working condition of the systemic ventricle (or single ventricle in this case) with the remainder of the vasculature. ${ }^{21}$ In particular, the peak of the forward compression wave (FCW) in early systole and the peak of the forward expansion wave (FEW) at end systole on the net wave intensity pattern have been shown to be indicators of ventricular performance, relating to maximum rate of pressure rise and diastolic time constant $\tau$, respectively. ${ }^{22}$ An example is provided in Figure 2, $B$.

The relationship between the wave intensity parameters and both dimensional and functional parameters and the relationship between aortic distensibility and patient age were investigated.

\section{Statistical Analysis}

The data are presented as the mean \pm standard deviation after a normal distribution was tested using the Kolmogorov-Smirnoff test. Differences in the demographic and CMR variables between the mBT and Sano shunt groups were assessed using the unpaired $t$ test. Multivariate regression analysis was also performed to establish correlations between the parameters. $P<.05$ was taken as an indicator of statistical significance.

\section{RESULTS}

The average wave speed in this HLHS cohort was $7.1 \pm 2.5 \mathrm{~m} / \mathrm{s}$, translating into a value of aortic distensibility, $\mathrm{D}=3.6 \pm 2.7 \times 10^{-3} 1 / \mathrm{mm} \mathrm{Hg}$. No significant relationship $\left(\mathrm{R}^{2}<0.01, P=.94\right)$ was found between aortic distensibility and age (ie, a greater interval had elapsed from stage 1 palliation; Figure 3,A), suggesting that the loss of elasticity in the aorta occurs early but does not progress thereafter.

The dimensional analysis from the CMR-derived 3D volumes revealed that the $R_{\text {isthmus }}$ was $1.0 \pm 0.4$ (range, $0.4-2.1$ ), and the $R_{\text {arch }}$ was $0.3 \pm 0.1$ (range, $0.1-0.7$ ). This indicated a dominant size mismatch between the surgically repaired ascending or transverse aorta and the native descending aorta, rather than a localized narrowing at the level of the aortic isthmus, which was present only in some cases ( $R_{\text {isthmus }}<0.8$ only in 12 of 32 patients). As an indicator of ventricular performance, the peak of the FCW derived from the wave intensity analysis correlated significantly with the $R_{\text {arch }}\left(\mathrm{R}^{2}=0.23\right.$, $P=.006$ ); however, it did not correlate with the $R_{\text {isthmus }}$ $\left(\mathrm{R}^{2}<0.01, P=.6\right)$, as shown in Figure 3, $B$ and $C$. The peak of the FEW did not correlate with either of the area ratios. These observations were supported by the results of the multivariate regression analysis (Table 2). The patients with a reduced EF exhibited a significantly larger ventricular mass, shown by the correlation in Figure 3, $D\left(\mathrm{R}^{2}=0.28, P=.003\right)$.

The differences between the patients who had received an mBT shunt and those who had received a Sano shunt at the Norwood procedure were explored. The Sano shunt patients had a statistically significant lower $\mathrm{EF}(51 \% \pm 6 \%$ vs $57 \%$ $\pm 6 \%, P=.02)$, albeit unlikely of clinical significance. The end-diastolic volume did not differ significantly $(105 \pm 20$ $\mathrm{mL}$ in the Sano cohort vs $95 \pm 17 \mathrm{~mL}$ in the $\mathrm{mBT}$ shunt cohort, $P=.18$ ). Aortic distensibility was also not significantly different between the 2 groups $(4.3 \pm 3.2$ vs $3.1 \pm 2.2 \times 10^{-3} 1 / \mathrm{mm} \mathrm{Hg}, P=.26$ ); thus, both were equally affected by the presence of the patch in terms of aortic stiffness. Furthermore, the dimensions of the reconstructed arch as indicated by the $R_{\text {arch }}$ showed no difference in the extent of patching between the 2 groups 

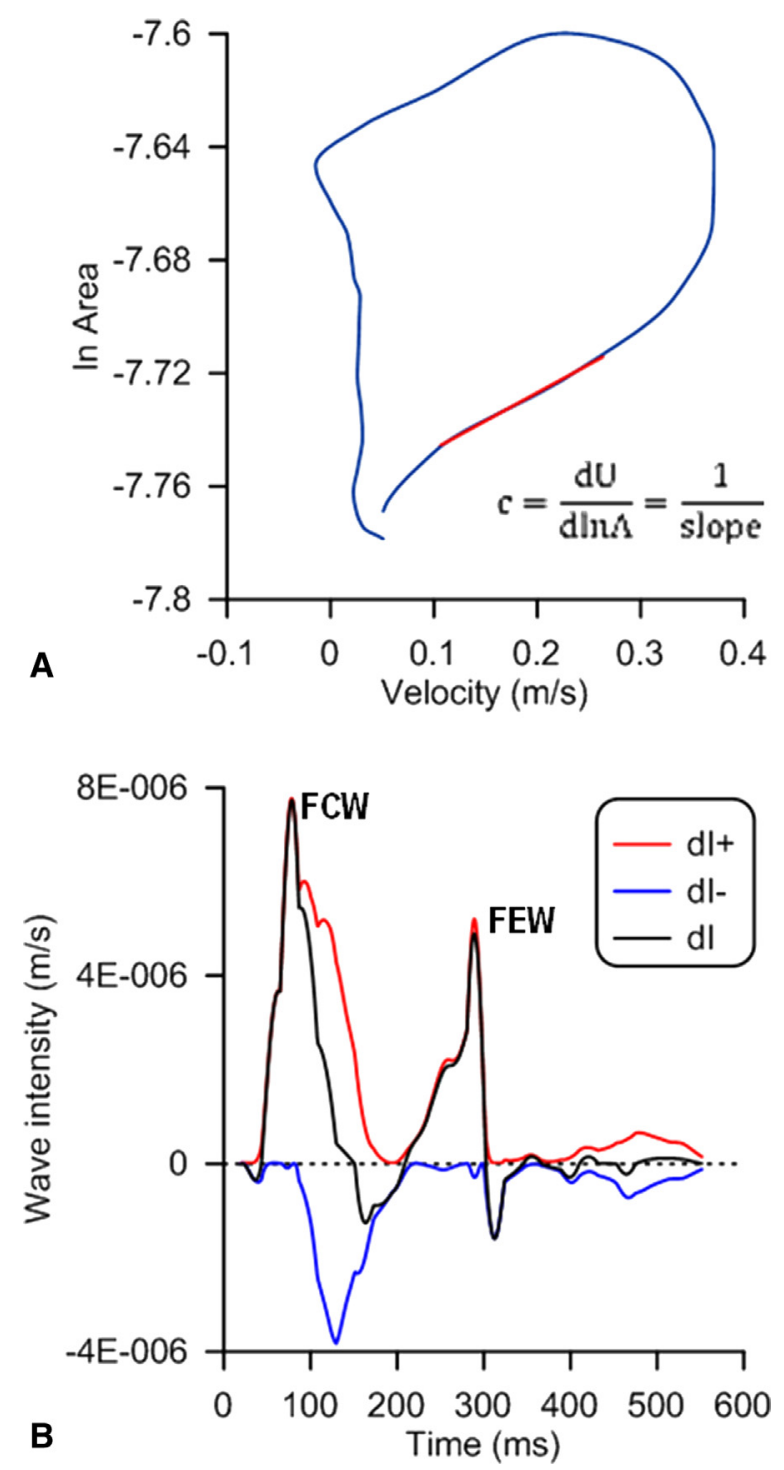

FIGURE 2. A, Calculation of wave speed $\mathrm{c}$ from the relationship between the velocity and area in the ascending aorta, with c yielded directly from the slope of the initial portion of the loop, when no reflected waves were expected in early systole. B, Sample of wave intensity $(d I)$ profile, including forward and backward wave intensity ( $d I+$ and $d I-$, respectively) separated by knowledge of the wave speed, ${ }^{19}$ highlighting the peaks of the forward compression wave $(F C W)$ in early systole and forward expansion wave $(F E W)$ at end systole.

$\left(R_{\text {arch }}=0.32 \pm 0.14\right.$ for $\mathrm{mBT}$ shunts and $0.29 \pm 0.11$ for Sano shunts, $P=.59$ ). Finally, neither the indexed single ventricle mass nor the FCW and FEW peaks varied significantly between the $\mathrm{mBT}$ and Sano shunt cohorts. All these comparisons are summarized in Figure 4.

\section{DISCUSSION}

The present study used CMR-derived wave intensity analysis, functional data, and $3 \mathrm{D}$ models to assess the ventricular mechanics in a population of patients with
HLHS. The wave intensity parameters-as surrogates of VA coupling-showed an overriding relationship between ventricular contractility and arch anatomy, with contractility unfavorably affected by a large surgically repaired transverse aorta. The coupling efficiency appeared not to be affected by the type of shunt placed at the Norwood procedure.

The present study has built on previous observations gathered from our group using a similar method, in which reduced aortic distensibility and disadvantageous VA coupling were observed in patients with HLHS with surgical aortic arch reconstruction at the Norwood procedure compared with other single ventricle children without arch reconstruction. ${ }^{9}$ The values of aortic distensibility, directly derived from the wave speed measurements, were of the same magnitude as those measured previously ${ }^{9}$ and published data. ${ }^{7}$ This has confirmed that in HLHS, the reconstructed ascending/transverse aorta will be less compliant than the native aortic tissue.

Although the present study was cross-sectional in design, we observed no trend for decreasing distensibility over time in the age range in which these investigations were performed (age range, 1.6-5.3 years, all patients before Fontan completion). This suggests that the changes in aortic distensibility related to arch reconstruction occur early after stage 1 but do not seem to progress considerably beyond. Furthermore, observing the relatively small variation in oxygen saturation across the studied patient population $(88 \% \pm 4 \%)$, we can consider the effect of the variations in hematocrit to not be a determinant factor in the calculations of aortic distensibility, although changes in the hematocrit would be reflected in the changes in $\rho$.

The single ventricle is very sensitive to afterload changes, and increased afterload in this setting can occur for different reasons. For example, increased afterload secondary to recurrent significant coarctation has been known to cause ventricular hypertrophy followed by ventricular systolic failure in children with HLHS and that relief of recoarctation leads to improved cardiac systolic function. ${ }^{23}$ Our study has shown that the additional anatomic factors related to aortic arch reconstruction can also cause increased impedance and, consequently, greater afterload to the single ventricle in HLHS. Although techniques have been described for reconstructing the aortic arch using solely autologous tissue, ${ }^{24}$ most surgeons will use some form of patch, with considerable variations in the extent of the patch. The size of the reconstructed aorta seems to be important, because patients with dilated reconstructed aortas appear to experience increased afterload compared with patients with more uniform dimensions between the reconstructed aortic arch and the aortic isthmus. A significant correlation was identified between the peak FCW (a wave intensity parameter surrogate for the 

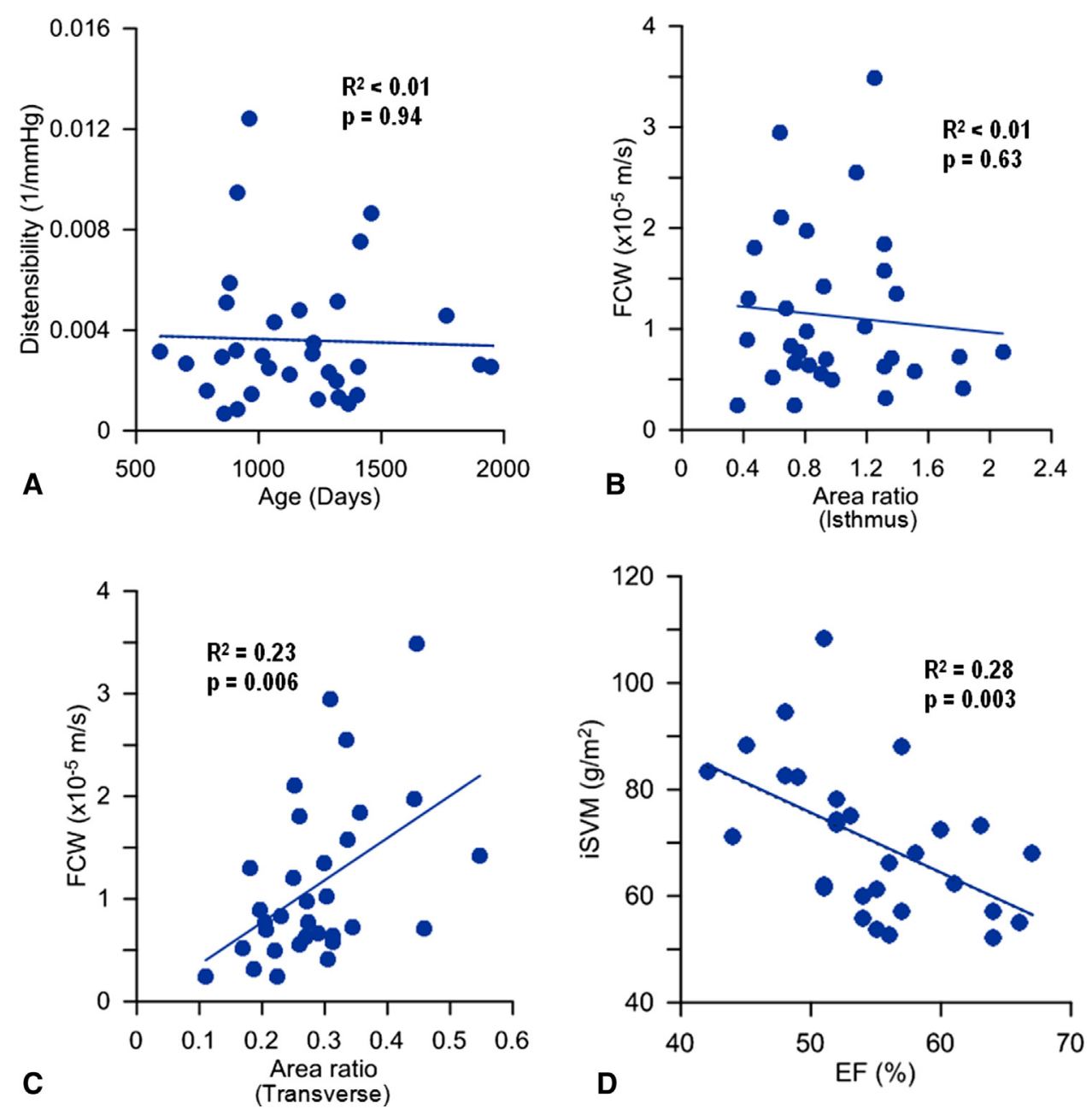

FIGURE 3. A, No relationship was found between the aortic distensibility and the interval from the Norwood procedure (approximately indicated by patient age at scanning). B, No relationship was found between the area ratio of the isthmus to the descending aorta $\left(R_{\text {ishtmus }}\right)$ and the peak of the forward compression wave $(F C W)$ as an indicator of the ventricular maximum rate of pressure rise. C, A significant correlation was found between the peak FCW and the area ratio of the isthmus to the surgically enlarged transverse arch $\left(R_{\text {arch }}\right)$, as an indicator of the size mismatch between the reconstructed aortic arch and the native descending aorta. D, A significant correlation indicated that patients with a lower ejection fraction $(E F)$ also exhibited greater values of the indexed single ventricle mass $(i S V M)$.

maximum rate of pressure rise ${ }^{22}$ ) and the size mismatch between the transverse and descending aorta. The extent of surgical reconstruction appears to affect ventricular contractility more than the presence of coarctation itself, because the ratio of the isthmus and descending aortic dimensions did not correlate with the peak FCW. Ventricular filling, instead, of which peak FEW is an indicator, appeared overall to not be affected by either dimensional parameter.

These observations were supported by the significant correlation found between the indexed single ventricular mass and single ventricular EF, indicating that those patients with poorer systolic cardiac function will present with more hypertrophied ventricles. This could also be linked to the loss in aortic distensibility, because it has been observed that the reconstructed aorta of palliated patients with HLHS presents with abnormally high elastance, which, as the reciprocal of compliance and a determinant of afterload, negatively affects the $\mathrm{EF}^{25}$

The shunt type can also have an effect on ventricular mechanics. RV myocardial deformation can be reduced at the ventriculotomy site in patients who have undergone a $\mathrm{RV}$-pulmonary artery conduit at stage $1,{ }^{26}$ and greater remodeling of the ventricular myocardial extracellular matrix has been observed in patients with a Sano shunt in a small histologic study. ${ }^{27}$ However, current evidence on the differences between the mBT and Sano shunts in terms of ventricular performance has been defined as "weak." 28 In our study, the Sano patients only exhibited a slightly lower single ventricular EF, unlikely of clinical relevance. In contrast, no significant differences were found between shunt type for aortic distensibility, ventricular mass, or the 
TABLE 2. Multivariate regression analysis results

\begin{tabular}{lcc}
\hline \multicolumn{1}{c}{ Multivariate regression } & $\mathbf{R}^{\mathbf{2}}$ & $\boldsymbol{P}$ value \\
\hline Dependent variable & & \\
$\quad$ Peak FCW & & \\
Independent variables & 0.270 & .067 \\
$\quad$ Aortic distensibility & 0.197 & .240 \\
Ejection fraction & 0.477 & $.010^{*}$ \\
Area ratio, arch $\left(R_{\text {arch }}\right)$ & -0.087 & .175 \\
$\quad$ Area ratio, isthmus $\left(R_{\text {isthmus }}\right)$ & 0.37 & $.012^{*}$ \\
Model summary & & \\
Dependent variable & & \\
Peak FEW & & \\
Independent variables & -0.089 & .467 \\
$\quad$ Aortic distensibility & 0.031 & .626 \\
Ejection fraction & 0.218 & .135 \\
Area ratio, arch $\left(R_{\text {arch }}\right)$ & -0.109 & .314 \\
Area ratio, isthmus $\left(R_{\text {isthmus }}\right)$ & 0.099 & .572 \\
Model summary & & \\
\hline FCW, Foced comps
\end{tabular}

FCW, Forced compression wave; $F E W$, forward expansion wave. *Statistically significant.

dimensions of the reconstructed arch, suggesting an overall similar impedance was experienced by the single ventricle in both groups. This was demonstrated by the wave intensity results, because the wave intensity peaks (both FCW and
FEW) as indicators of ventricular function did not highlight a worsening in VA coupling in the Sano cohort. This was in agreement with evidence suggesting that no adverse effects of ventriculotomy on the performance of the single ventricle result during short- and medium-term follow-up with the Sano modification of the Norwood procedure. ${ }^{28}$

Our findings were determined using a noninvasive method, with the wave intensity peaks as surrogates for VA coupling. A very recent study ${ }^{25}$ has corroborated our results by showing unfavorable VA coupling in an HLHS population using the pressure-volume conductance system, although their observations focused on a group of patients after stage 3 surgery, and we have gathered insight before Fontan completion.

\section{CONCLUSIONS}

In our population of children with operated HLHS, VA coupling was affected by aortic arch size mismatch owing to surgical enlargement of the hypoplastic aorta, rather than aortic coarctation at the isthmus. In contrast, it was not affected by the type of shunt placed at the Norwood operation. Overall, these observations suggest the opportunity for the surgeon to idealize the repair, such that the patch material and extent could be limited, and
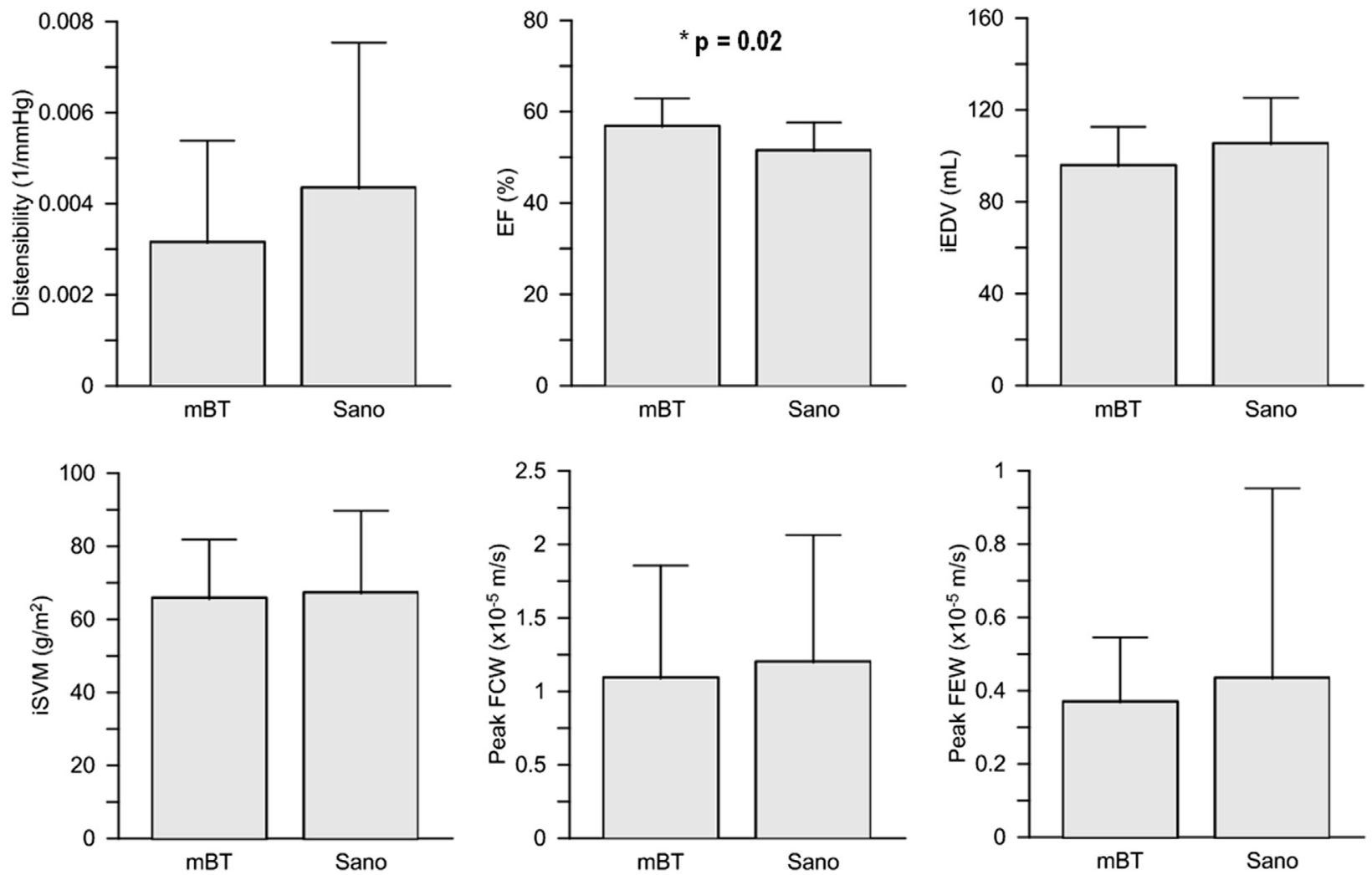

FIGURE 4. Differences between patients with modified Blalock-Taussig $(m B T)$ shunt and Sano shunt at the Norwood procedure were evaluated in terms of the following parameters: aortic distensibility, ejection fraction $(E F)$, indexed end-diastolic volume ( $i E D V)$, indexed end-systolic volume ( $i E S V)$, and-from the wave intensity analysis results—-peak forward compression wave $(F C W)$ and peak forward expansion wave $(F E W)$. iSVM, Indexed single ventricle mass. 
the ascending aorta and aortic arch complex tailored optimally, potentially having a beneficial effect on hemodynamic energy transmission and ventricular function and durability.

\section{References}

1. Altmann K, Printz BF, Solowiejczky DE, Gersony WM, Quaegebeur J, Apfel HD. Two-dimensional echocardiographic assessment of right ventricular function as a predictor of outcome in hypoplastic left heart syndrome. Am J Cardiol. 2000;86:964-8.

2. Stieh J, Fischer G, Scheewe J, Uebing A, Dütschke P, Jung O, et al. Impact of preoperative treatment strategies on the early perioperative outcome in neonates with hypoplastic left heart syndrome. J Thorac Cardiovasc Surg. 2006;131: 1122-9.e2.

3. Muthurangu V, Taylor AM, Hegde SR, Johnson R, Tulloh R, Simpson JM, et al. Cardiac magnetic resonance imaging after stage I Norwood operation for hypoplastic left heart syndrome. Circulation. 2005;112:3256-63.

4. Norwood WI Jr. Hypoplastic left heart syndrome. Ann Thorac Surg. 1991;52: 688-95.

5. Pigott JD, Murphy JD, Barber G, Norwood WI. Palliative reconstructive surgery for hypoplastic left heart syndrome. Ann Thorac Surg. 1988;45:122-8.

6. Mahle WT, Rychik J, Weinberg PM, Cohen MS. Growth characteristics of the aortic arch after the Norwood operation. J Am Coll Cardiol. 1998;32:1951-4.

7. Voges I, Jerosch-Herold M, Hedderich J, Westphal C, Hart C, Helle M, et al. Maladaptive aortic properties in children after palliation of hypoplastic left heart syndrome assessed by cardiovascular magnetic resonance imaging. Circulation. 2010;122:1068-76.

8. Cardis BM, Fyfe DA, Mahle WT. Elastic properties of the reconstructed aorta in hypoplastic left heart syndrome. Ann Thorac Surg. 2006;81:988-91.

9. Biglino G, Schievano S, Steeden JA, Ntsinjana H, Baker C, Khambadkone S, et al. Reduced ascending aorta distensibility relates to adverse ventricular mechanics in patients with hypoplastic left heart syndrome: noninvasive study using wave intensity analysis. J Thorac Cardiovasc Surg. 2012;144:1307-13; discussion 1313-4.

10. Sundareswaran KS, Kanter KR, Kitajima HD, Krishnankutty R, Sabatier JF, Parks WJ, et al. Impaired power output and cardiac index with hypoplastic left heart syndrome: a magnetic resonance imaging study. Ann Thorac Surg. 2006; 82:1267-75; discussion 1275-7.

11. Yuan SM, Shinfeld A, Raanani E. The Blalock-Taussig shunt. J Card Surg. 2009; 24:101-8.

12. Sano S, Ishino K, Kawada M, Arai S, Kasahara S, Asai $\mathrm{T}$, et al. Right ventricle-pulmonary artery shunt in first-stage palliation of hypoplastic left heart syndrome. J Thorac Cardiovasc Surg. 2003;126:504-9; discussion 509-10.

13. Ohye RG, Sleeper LA, Mahony L, Newburger JW, Pearson GD, Lu M, et al. Comparison of shunt types in the Norwood procedure for single-ventricle lesions. N Engl J Med. 2010;362:1980-92.
14. Fischbach J, Sinzobahamvya N, Haun C, Schindler E, Zartner P, Schneider M et al. Interventions after Norwood procedure: comparison of Sano and modified Blalock-Taussig shunt. Pediatr Cardiol. 2013;34:112-8.

15. Raja SG, Atamanyuk I, Tsang VT. Impact of shunt type on growth of pulmonary arteries after Norwood stage I procedure: current best available evidence. World J Pediatr Congenit Heart Surg. 2011;2:90-6.

16. Menon SC, Erickson LK, McFadden M, Miller DV. Effect of ventriculotomy on right-ventricular remodeling in hypoplastic left heart syndrome: a histopathological and echocardiography correlation study. Pediatr Cardiol. 2013;34:354-63.

17. Rosset A, Spadola L, Ratib O. OsiriX: an open-source software for navigating in multidimensional DICOM images. J Digit Imaging. 2004;17: 205-16.

18. Schievano S, Migliavacca F, Coats L, Khambadkone S, Carminati M, Wilson N, et al. Percutaneous pulmonary valve implantation based on rapid prototyping of right ventricular outflow tract and pulmonary trunk from MR data. Radiology. 2007;242:490-7.

19. Lemler MS, Zellers TM, Harris KA, Ramaciotti C. Coarctation index: identification of recurrent coarctation in infants with hypoplastic left heart syndrome after the Norwood procedure. Am J Cardiol. 2000;86:697-9.

20. Biglino G, Steeden JA, Baker C, Schievano S, Taylor AM, Parker KH, et al. A non-invasive clinical application of wave intensity analysis based on ultrahigh temporal resolution phase-contrast cardiovascular magnetic resonance. J Cardiovasc Magn Reson. 2012;14:57.

21. Parker KH. An introduction to wave intensity analysis. Med Biol Eng Comput 2009; 47:175-88.

22. Ohte N, Narita H, Sugawara M, Niki K, Okada T, Harada A, et al. Clinical usefulness of carotid arterial wave intensity in assessing left ventricular systolic and early diastolic performance. Heart Vessels. 2003;18:107-11.

23. Larrazabal LA, Selamet Tierney ES, Brown DW, Gauvreau K, Vida VL, Bergersen L, et al. Ventricular function deteriorates with recurrent coarctation in hypoplastic left heart syndrome. Ann Thorac Surg. 2008;86:869-74.

24. Fraser CD Jr, Mee RB. Modified Norwood procedure for hypoplastic left heart syndrome. Ann Thorac Surg. 1995;60:S546-9.

25. Schlangen J, Fischer G, Petko C, Hansen JH, Voges I, Rickers C, et al. Arterial elastance and its impact on intrinsic right ventricular function in palliated hypoplastic left heart syndrome. Int J Cardiol. 2013;168:5385-9.

26. Menon SC, Minich LL, Casper TC, Puchalski MD, Hawkins JA, Tani LY Regional myocardial dysfunction following Norwood with right ventricle to pulmonary artery conduit in patients with hypoplastic left heart syndrome. J Am Soc Echocardiogr. 2011;24:826-33.

27. Padalino MA, Castellani C, Toffoli S, Della Barbera M, Milanesi O, Thiene G et al. Pathological changes and myocardial remodelling related to the mode of shunting following surgical palliation for hypoplastic left heart syndrome. Cardiol Young. 2008;18:415-22.

28. Raja SG, Atamanyuk I, Kostolny M, Tsang V. In hypoplastic left heart patients is Sano shunt compared with modified Blalock-Taussig shunt associated with deleterious effects on ventricular performance? Interact Cardiovasc Thorac Surg. 2010;10:620-3. 